\title{
Conversion attribution in the online environment - identification of crucial decision path stages. Theory and case study
}

\author{
Atrybucja konwersji w środowisku internetowym — identyfikacja \\ kluczowych etapów decyzyjnych. Teoria oraz studium przypadku
}

\author{
mgr Arkadiusz Zaremba \\ doktorant na Wydziale Zarządznia Uniwersytetu Warszawskiego \\ ORCID: 0000-0002-6174-798X \\ e-mail: arkadiusz.zaremba@gmail.com
}

\begin{abstract}
This paper presents a review of marketing theories on the topic of consumer behaviour from the perspective of the consumer and the marketer and its adaptation to the online advertising environment. As previous researches have shown, there is a strong need to verify these theories in practice using real consumer data, and not surveys conducted among students — as most researchers do. In order to show the complexity of online advertising and measurement tools, 565 real online consumer journey paths were analysed using several most popular conversion attribution models. The results confirm that classical decision making processes are still suitable to current consumer behaviour but there exist many difficulties in indicating channels responsible for particular decision making process stages and technology limitations require some further research.
\end{abstract}

Keywords

conversion attribution, customer journey, online conversion path, online decision making process, impact of online media

Artykuł prezentuje przegląd teorii w zakresie zachowań konsumenckich, wraz z ich adaptacją do warunków środowiska reklamy internetowej, jednocześnie z perspektywy konsumenta oraz marketera. Poprzednie badania naukowe w tym obszarze wskazywały na silną potrzebę weryfikacji teorii zachowania konsumentów w obszarze internetowym poprzez wykorzystanie obserwacji realnych zachowań konsumentów. Aby pokazać złożoność narzędzi reklamy internetowej i sposobów pomiaru, dokonano analizy 565 ścieżek decyzyjnych realnych konsumentów z wykorzystaniem kilku popularnych modeli atrybucji. Wyniki potwierdzają, że klasyczne modele decyzyjne są wciąż zbieżne z obecnymi zachowaniami konsumenckimi w środowisku internetowym, jednakże należy pamiętać o wielu trudnościach związanych z analizą wpływu poszczególnych kanałów reklamowych na podejmowanie decyzji przez konsumenta oraz ograniczeniach technologicznych, co wymaga dalszych badań.

\section{Stowa kluczowe}

atrybucja konwersji, ścieżka decyzyjna klienta, ścieżka konwersji online, proces podejmowania decyzji online, wpływ mediów internetowych

JEL: M310

str. $15-29$

\section{References}

Abhishek, V., Fader, P., \& Hosangar, K. (2012). Media Exposure through the Funnel: A Model of Multi-Stage Attribution. http://dx.doi.org/10.2139/ssrn.2158421

Anderl, E., Becker, I., Wangenheim, F. V., \& Schumann, J. H. (2014). Mapping the Customer Journey: A Graph-based Framework for Online Attribution. https://papers.ssrn.com/sol3/papers.cfm?abstract_id=2343077 
Bath, S., Bevans, M., \& Sengupta, S. (2002). Measuring Users' Web Activity to Evaluate and Enhance Advertising Effectiveness. Journal of Advertising, 31, 97-106. https://doi.org/10.1080/00913367.2002.10673679

Danaher, P. J. \& Dagger, T. S. (2013). Comparing the Relative Effectiveness of Advertising Channels: A Case Study of Multimedia Blitz Campaign. Journal of Marketing Research, 50(4), 517-534. https://doi.org/10.1509/jmr.12.0241

Darley, W. K., Blankson, C., \& Luethge, D. J. (2010). Toward an Integrated Framework for Online Consumer Behavior and Decision Making Process: A Review. Psychology and Marketing, 27(2), 94-116. https://doi.org/10.1002/mar.20322

Gędek, M. (2013). Reklama. Zarys problematyki. Lublin: Wyd. KUL.

Howard, J. A. \& Sheth, J. (1969). The Theory of Buyer Behaviour. Journal of the American Statistical, (January), 467-473.

Jayawardane, C. H. W., Halgamuge, S. K., \& Kayande, U. (2015). Attributing Conversion Credit in an Online Environment: An Analysis and Classification. Proceedings from the 3rd International Symposium on Computational and Business Intelligence (ISCBI). Retrived from https://www.researchgate.net/publication/304294477_Attributing_Conversion_ Credit_in_an_Online_Environment_An_Analysis_and_Classification

Kall, J. (2002). Reklama. Warszawa: PWE.

Kaznowski, D. (2007). Marketing $w$ Internecie. Warszawa: Difin.

Lecinski, J. (2011). Winning the Zero Moment of Truth. Google.

Lemon, K. N. \& Verhoef, P. C. (2016). Understanding Customer Experience Throughout the Customer Journey. Journal of Marketing: AMA/MSI Special Issue, 80, 69-96. https://doi.org/10.1509/jm.15.0420

Li, H. A. \& Kannan P. K. (2014). Attributing Conversions in a Multichannel Online Marketing Environment: An Empirical Model and a Field Experiment. Journal of Marketing Research, 51(1), 40-56. https://doi.org/10.1509/jmr.13.0050

Peter, J. P. \& Olson, J. C. (1990). Consumer Behavior and Marketing Strategy. Boston: Irwin.

Pomirlenau, N., Schibrovsky, J. A., Peltier, J., \& Nill, A. (2013). A Review of Internet Marketing Research over the Past 20 Years and Future Research Direction. Journal of Research in Interactive Marketing, 7, 166-181. https://doi.org/ 10.1108/JRIM-01-2013-0006

Rudnicki, L. (2012). Zachowania konsumentów na rynku. Warszawa: PWE.

Shao, X. \& Li, L. (2011). Data-driven Multi-touch Attribution Model. Proceedings from the 17th ACM SIGKDD International Conference on Knowledge Discovery and Data Mining. San Diego. https://doi.org/10.1145/ 2020408.2020453

Solomon M. R. (2013). Consumer Behavior. Buying, Having and Being. Harlow: Pearson.

Srinivasan, S., Rutz, O. J., \& Pauwels, K. (2016). Paths to and off Purchase: Quantifying the Impact of Traditional Marketing and Online Consumer Activity. Journal of the Academic Marketing Science, 44, 440-453. https://doi.org/10.1007/ s11747-015-0431-z

Yadagiri, M. M., Saini, S. K., \& Sinha, R. (2015). A Non-parametric Approach to the Multichannel Attribution Problem. Web Information Systems Engineering, 9418, 338-352.

Zantedeschi, D, Feit, E. M., \& Bradlow, E. (2017). Measuring Multi-channel Advertising Response. Management Science, 63(8), 2706-2728. https://doi.org/10.1287/mnsc.2016.2451 